\title{
PREDICTION OF ARTERIAL CARBON DIOXIDE TENSION DURING CONTROLLED VENTILATION WITH A MODIFIED MAPLESON D SYSTEM*
}

\author{
J.A. Bain and W.E. SPOEREL $\nmid$
}

The observation that relatively low fresh gas inflows are adequate for $\mathrm{CO}_{2}$ removal under anaesthesia, ${ }^{3}$ led to the adoption of a modified Mapleson D system as a universal anaesthetic breathing circuit (Figure 1). ${ }^{1}$ For routine clinical use a fresh gas inflow of $70 \mathrm{ml} / \mathrm{kg}$ body weight was found satisfactory and in adult patients on controlled ventilation produced an average arterial carbon dioxide tension of $36.6 \mathrm{~mm} \mathrm{Hg}^{2}$

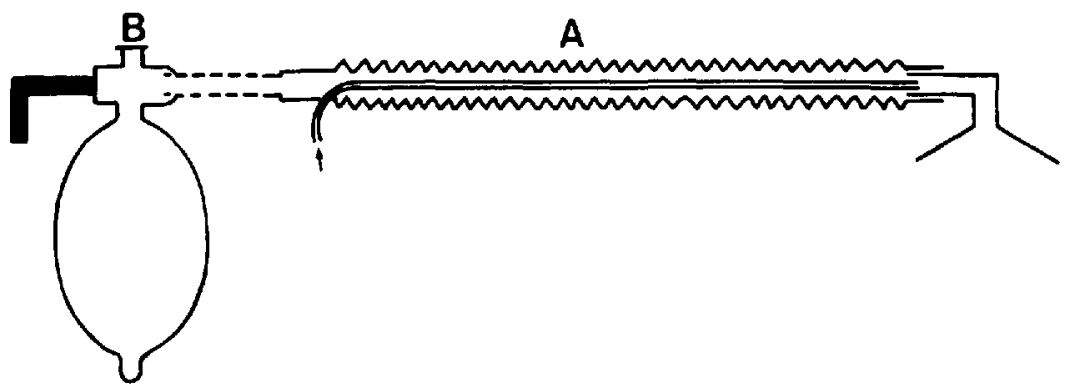

Figure 1. Modified Mapleson D Circuit: A-double lumen breathing tube. B-bagmount and blowoff valve. $\uparrow$-fresh gas inflow.

Since the arterial $\mathrm{CO}_{2}$ level has a controlling influence on ccrebral blood flow, a predictable arterial Pco. would be particularly useful in anaesthetic procedures for neurosurgery. Hypocarbia, by inducing cerebral vasoconstriction, is known to reduce the volume of the brain and also to facilitate cerebral angiography by providing a clearer picture due to the greater density of contrast medium. ${ }^{4}$ Hypercarbia produces ccrebral vasodilation and is therefore advocated for surgical procedures involving occlusion of one internal carotid artery. ${ }^{4}$

In a system which allows complete mixing of the fresh gas inflow with alveolar gas, the concentration of carbon dioxide in the alveoli $\left(\mathrm{F}_{\mathrm{ACO}}\right)$ at any one time is determined by the carbon dioxide production $\left(\mathrm{VCO}_{2}\right)$ and by the fresh gas inflow (VF), according to the simple relationship:

$\mathrm{F}_{\mathrm{ACO}} \mathrm{C}_{2}=\mathrm{VCO}_{2} / \mathrm{VF}$

For this assumption it is necessary that the volume of pulmonary ventilation is greater than the respiratory minute volume predicted by the Radford nomogram ${ }^{7}$ and consequently exceeding considerably the inflow volume of fresh gas. If such conditions exist the fresh gas inflow will determine the level of arterial Pco.. for

'Presented at the Annual Meeting of the Canadian Anaesthetists' Society, St. John's, Newfoundland, June 17-20, 1974.

tDepartment of Anaesthesia, University of Western Ontario and Victoria Hospital and University Hospital, London, Canada.

Canad. Anaesth. Soc. J., vol. 22, no. 1, January 1975 
a given $\mathrm{CO}_{2}$ production, i.e. for any fresh gas inflow below the volume of pulmonary ventilation the arterial $\mathrm{PCO}_{2}$ should rise or fall to a plateau determined by the patient's $\mathrm{CO}_{2}$ production. Assuming a normal metabolic rate, this would allow us to construct a curve relating the patient's carbon dioxide level to the fresh gas inflow and to use it for the prediction of the arterial $\mathrm{PCO}_{2}$ in clinical situations.

\section{METHOD}

Determinations of arterial $\mathrm{PCO}_{2}$ in 132 patients were used for the construction of a curve relating fresh gas inflow and $\mathrm{Pco}_{2}$ (Figure 2). These patients, ranging in age from 20 to 70 years, were undergoing elective surgical procedures and were assessed as risk one or two in the classification of The American Society of Anesthesiologists. Patients with elevation of body temperature were excluded as were patients with disease conditions which could possibly influence body metabolism. Patients were either lightly premedicated with opiates (pethidine $75 \mathrm{mg}$ or less) or valium or received no depressant medication. Anaesthesia was induced with sodium thiopentone and maintained with nitrous oxide and oxygen in a ratio of $5: 2$ supplemented by halothane ( 1 per cent or less) or intravenous opiates. After tracheal intubation and manual ventilation with a gas flow of five litres of nitrous oxide and two litres oxygen per minute, the patient was ventilated with a bellowstype ventilator (Air Shields Ventilator Ventimeter) with a tidal volume of at least

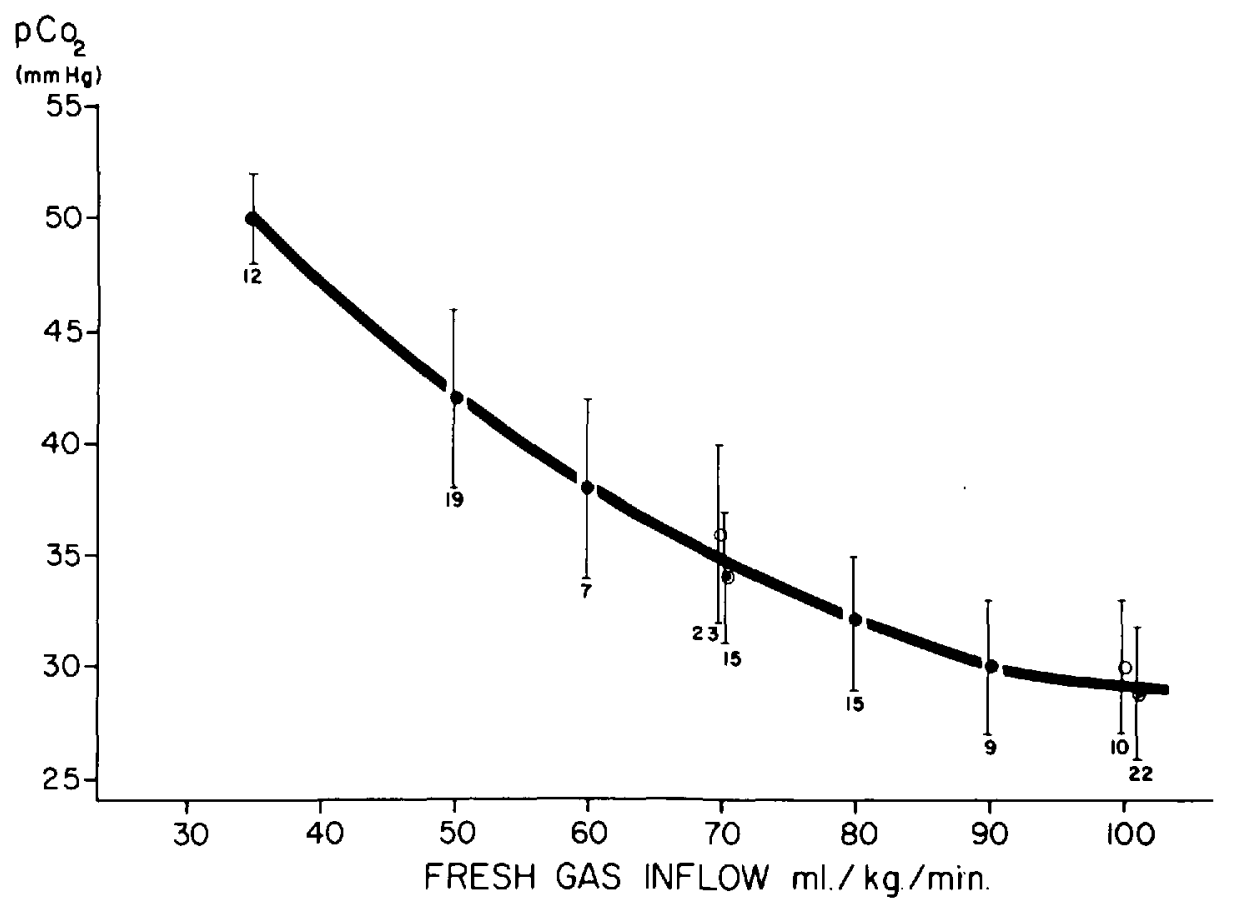

Figure 2. Fresh gas inflow in relation to arterial $\mathbf{P C O}_{2}$. The figures indicate the number of patients at a given inflow of fresh gas. $I=$ standard deviation. At inflow rates of 70 and 100 $\mathrm{ml} / \mathrm{kg}$ body weight, male $(0)$ and female $(\theta)$, have been separated. 
$10 \mathrm{ml} / \mathrm{kg}$ body weight and a rate of 12 to 16 breaths per minute. When anaesthesia was stabilized the fresh gas inflow was adjusted to the desired level, ranging between 35 and $100 \mathrm{ml} / \mathrm{kg}$ body weight, by setting the gas flow as closely as possible to the calculated value on the relatively crude flowmeters of a clinical gas machine. Thirty to forty-five minutes after the desired inflow had been started a blood sample was drawn and the arterial $\mathrm{PCO}_{2}$ was determined.

\section{Results}

Figure 2 shows the relationship between the fresh gas inflow in $\mathrm{ml} / \mathrm{kg}$ body weight and the arterial Pco.2 observed. For each fresh gas inflow the average and the standard deviation is given and the number of determinations is indicated in brackets below each point. At the inflow rates of 70 and $100 \mathrm{ml} / \mathrm{kg}$ male and female patients have been separated to show that the average for female patients was 1 to $2 \mathrm{~mm}$ lower; this difference was not significant and is well within the possible errors of our method.

\section{Discussion}

The data presented show that when using the modified Mapleson D system the arterial $\mathrm{PCO}_{2}$ can be predicted from the fresh gas inflow in a given patient on controlled ventilation to a degree that is useful in clinical practice. At the same time, it is noted that there is a considerable spread in the $\mathrm{CO}_{2}$ levels for each rate of inflow, resulting in relatively large standard deviations. These might be reduced by greater standardization of patient management and anaesthetic technique and by more finely calibrated flowmeters. However, it should be noted that our deviations are of the same order as those on which other investigators have based nomograms predicting ventilation $(6,7)$. Our data did not seem to warrant a separation into male and female patients since the observed differences were within the errors of the technique used.

Graphs and a slide rule type predictor for the alveolar ventilation required on the basis of an estimated CO.2 production were published by Nunn. ${ }^{5}$ Assuming that the volumes of fresh gas inflow in our breathing circuit are close to the volume of the alveolar ventilation, we thought the blood gas predictor by Nunn (manufactured by British Oxygen Corporation) could possibly be used to predict arterial $\mathrm{PCO}_{2}$ levels in our circumstances.

The values obtained for a $70 \mathrm{~kg}$ patient using Nunn's blood gas predictor are shown in Figure 3 together with the curve in Figure 2. For his calculations, Nunn made the assumption that under anaesthesia the metabolic rate would be 85 per cent of the patient's basal rate. Predictions of $\mathrm{PCO}_{2}$ on this basis are shown in the interrupted curve on the left in Figure 3, while the interrupted curve on the right represents predictions based on 100 per cent of the basal metabolic rate. It can be seen that in the area of the flow rates which we had recommended for clinical use ${ }^{2}$ these predictions are in agreement with our findings. However, we find that the rise in $\mathrm{PCO}_{2}$ in our cases is significantly less when the fresh gas inflow is decreased 


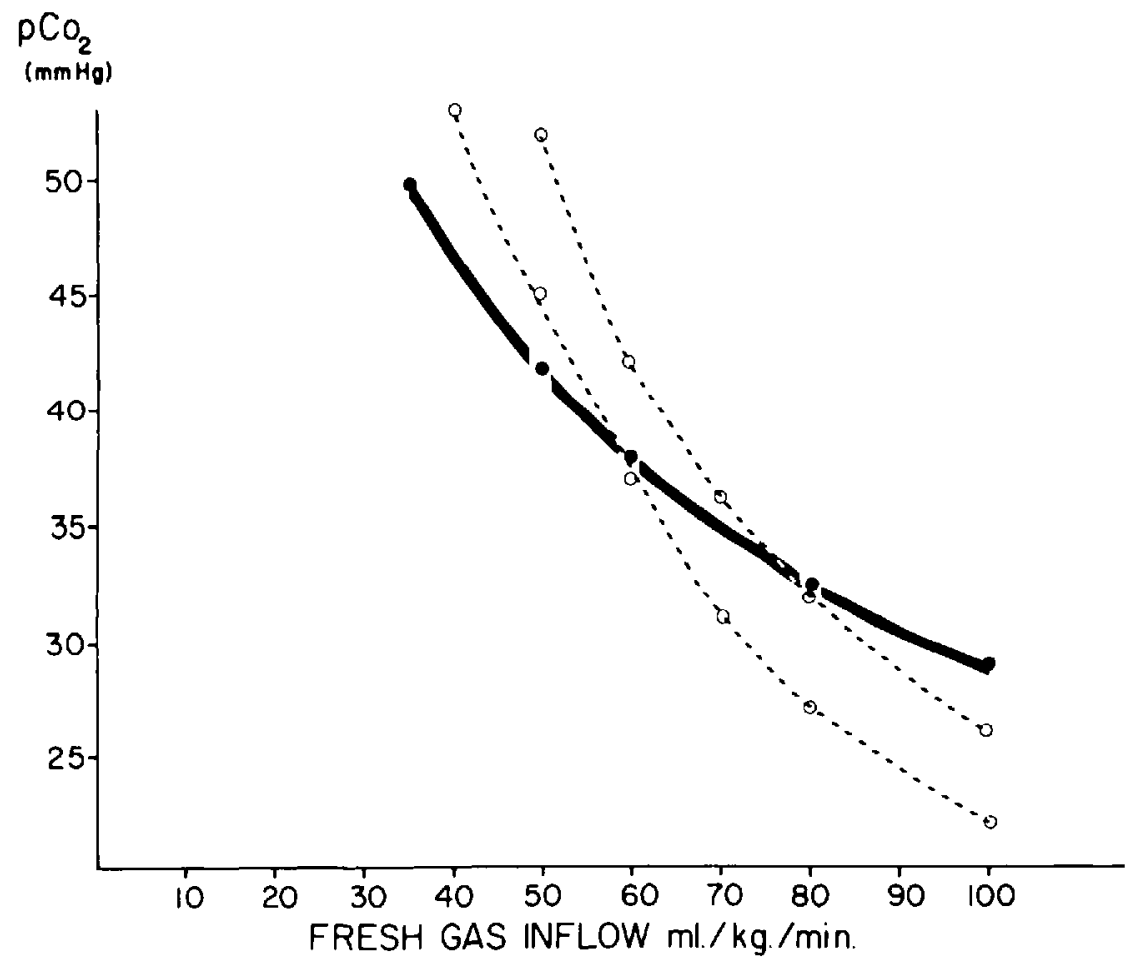

Figure 3. Fresh gas inflow related to arterial Pco..2 (solid curve) and requirements for alveolar ventilation according to the Blood Gas Predictor by Nunn, calculated for 85 per cent (left interrupted curve) and 100 per cent (right interrupted curve) of basal metabolic rate.

and that the observed fall in $\mathrm{PCO}_{2}$ is less than predicted when the fresh gas inflow is increased. At present we have no satisfactory explanation for this discrepancy.

\section{SUMMARY}

Based on measurements of arterial $\mathrm{CO}_{2}$ tension in 132 adult patients, a curve was constructed relating fresh gas inflow and arterial $\mathrm{CO}_{2 .}$ tension for a modified Mapleson D system. In patients on controlled ventilation using a ventilating volume greater than the predicted respiratory minute volume, it was found that the arterial $\mathrm{PCO}_{2}$ can be predicted from the fresh gas inflow with an accuracy sufficient to be clinically useful.

\section{RÉSUMÉ}

Nous basant sur la mesure du Pco.. artériel chez 132 adultes, nous avons établi une courbe de prédiction de la $\mathrm{PaCO}_{2}$ par rapport au volume de gaz frais introduit dans un système Mapleson D modifié.

Chez ces malades sous respiration contrôlée avec des volumes de ventilation plus grands que les volumes-minute prédits, nous avons trouvé que les $\mathrm{PaCO}_{2}$ peuvent 
être prédits avec assez de précision pour usage clinique à l'aide de notre courbe basée sur le volume de gaz frais administré.

\section{BIBLIOGRAPHY}

1. Bain, J.A. \& Spoerel, W.E. A streamlined anaesthetic system. Can. Anaes. Soc. J. 19: 426 (1972).

2. Bain, J.A. \& Spozrel, W.E. Flow requirements for a modified Mapleson D system during controlled ventilation. Can. Anaes. Soc. J. 20:629 (1972).

3. KaIN, M.L. \& NunN, J.F. Fresh gas economics of the Magill circuit. Anaesthesiology 29: 964 (1968).

4. Michenfelder, J.D., Gronert, G.A., \& Rehder, K. Neuroanaesthesia (review article). Anesthesiology 30: 65 (1969).

5. NUNN, J.F. Anaesthesia 17: 182 (1962).

6. NUNN, J.F. Applied respiratory physiology. Butterworth, London (1969).

7. RADForo, E.P. Jr. Ventilation standards for use in artificial respiration. J. Applied Physi$\operatorname{ology} 7: 451$ (1955). 